\title{
Contribution to the snow protection solutions for pitched roofs
}

\author{
Jozef Oláh $^{1}$ and Michal Šida ${ }^{1, *}$ \\ ${ }^{1}$ Slovak University of Technology in Bratislava, Faculty of Civil Engineering, Radlinského 11, \\ 81005 Bratislava, Slovakia
}

\begin{abstract}
This paper presents results of research conducted as part of doctoral dissertation. It deals with pitched roofs defects and failures caused by insufficient snow protection. It also assesses the most common snow retention systems in Slovakia in terms of holding strength and reliability. Selected snow retention systems that are used for different types of roofing were loaded by forces in a direction parallel to the roofing. Paper evaluates all tested snow retention systems and indicates their weaknesses. This paper also deals with friction coefficient between snow and the most commonly used roofing in Slovakia.
\end{abstract}

\section{Introduction}

Improper or wrong design of sloped roofs in snow and cold regions, under-dimensioned snow protection systems, leading to the roof damage or endangerment of people or property situated in the potential impact zones of snow or ice, is still reality in Slovakia. There are several reasons for this. The rules resulting from Slovak legislation, according to which the roof snow protection should be designed, is insufficient and unclear, in some cases even contradictory. On the one hand, there is an obligation to use snow retention system for roofs with a slope greater than $25^{\circ}$ (Decree of the Ministry of Environment of the Slovak Republic No. 532/2002) [1], on the other hand there is allowed falling snow off the sloped roofs according to standard STN 731901 [2] Designing of roofs. Slovak legislation defines no principles of snow retention system design and therefore engineers must rely solely on the recommendations of manufactures. Therefore, this doctoral dissertation was trying to point out pros and cons of the most commonly used types of snow retention systems in Slovakia by measurement of their holding strength and determine recommendations for design of snow retention systems based on findings of measurement of friction between snow and most commonly used roofing for sloped roofs in Slovakia [3-4].

\section{Measurement of snow retention systems holding strength}

One part of dissertation assignment was to measure holding strength of individual snow retention system elements under laboratory conditions, observe their weak points, evaluate measured results and compare them with values declared by the manufacturer.

\footnotetext{
* Corresponding author: sidaxmichal@gmail.com
} 


\subsection{Method}

Three samples of each snow retention system elements were subjected to the laboratory test. Each sample was installed to the test apparatus and loaded by forces in a direction parallel to the roofing. Loading test was cancelled for each element individually according to the test progress. Testing was performed at certified laboratory Microbac Laboratories, Inc., Boulder - Colorado, USA, using electro-mechanical universal testing machine SFM60. The effort was to select the most commonly used types of snow retention systems in Slovakia. New products, not used, were subjected to the test. A total of five types of snow retention systems were selected for the test.

- Snow fence type "A" - linear snow retention system consisting of a special tile, support bracket and snow fence, made of aluminium. This system is designed for tile roofing. Special aluminium tile is hooked over the tiling battens and screwed to them and support bracket is snapped on a tile.

- Snow fence type "B" - linear snow retention system consisting of universal support bracket and snow fence, made of galvanized steel with thickness of $4 \mathrm{~mm}$. The system is used for tile roofing. Support bracket is hooked over the tiling battens and screwed to them,

- Snow rail - linear snow retention system consisting of support bracket (consisting of two parts) and tubes made of galvanized steel. The system is designed for standing seam metal roof system. Bracket is attached to the standing seam by connecting of both parts over the standing seam and tightening the bolts,

- Snow strap - non-linear snow retention system consisting of hooks made of galvanized metal sheet. Snow guards are used for tile roofing and are hooked over the top of tiles,

- U-shaped snow guard - non-linear snow retention system consisting of snow U-shaped snow guards made of galvanized metal sheet. The system is used for corrugated metal roofing and snow guards are screwed to the metal roofing using screws with rubber seal.

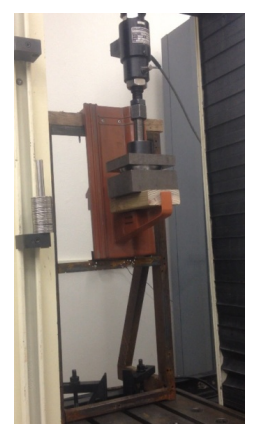

Fig. 1. Snow fence type "A".

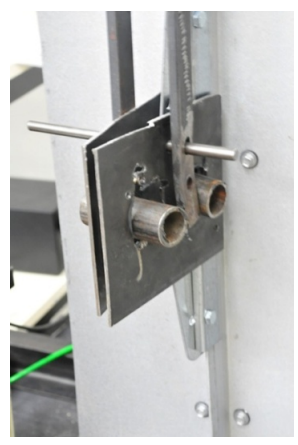

Fig. 4. Snow rail.

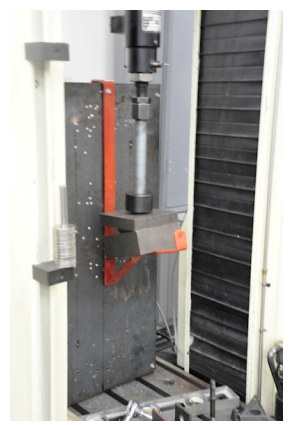

Fig. 2. Snow fence type "B".

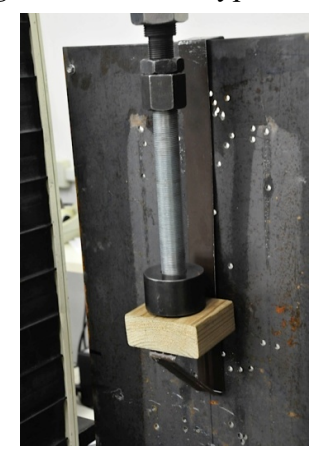

Fig. 5. Snow strap.

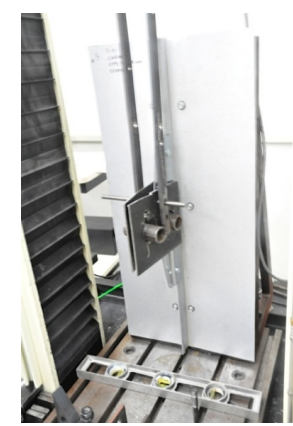

Fig. 3. Snow rail.

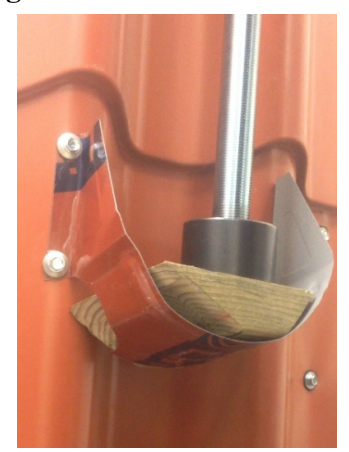

Fig. 6. Snow strap. 


\subsection{Results}

The most important findings observed during the laboratory testing are following:

\subsubsection{Snow fence type " $A$ "}

- The average ultimate strength of support bracket snapped to special tile determined by testing was $6,84 \mathrm{kN}$ and exceeded declared ultimate strength 4,0 $\mathrm{kN}$ approximately 1,7 times, which corresponds with safety factor specified by Austrian standard Önorm B 3418 - Design and construction of snow protection systems on roofs [5].

- The ultimate strength of the support bracket is given by strength of attachment to the battens, which failed during the testing.

\subsubsection{Snow fence type " $B$ "}

- Ultimate strength of individual tested support bracket varied widely, which could be caused either by measurement inaccuracies or different mechanical properties of tested brackets. The lowest value of ultimate strength was $1,36 \mathrm{kN}$.

- The ultimate strength of support bracket is given by quality of particular product - steel grade, quality of processing, storage, handling on construction site etc., since they were plastically deformed.

The manufacturers of both systems, snow fence type " $A$ " and " $B$ ", recommend to use them in combination with non-linear snow guards that help to retain a snow blanket over the entire roof surface. Based on this fact and experimental analysis, it can be stated that both tested linear systems are reliable in terms of their holding strength.

\subsubsection{Snow rail}

- The average maximum strength at which a displacement of support bracket with value of $1 \mathrm{~cm}$ along standing seam occurred was $4,63 \mathrm{kN}$.

- The holding strength of support bracket is given by tightening torque of bolts that are used to attach the support bracket to the standing seam. Of course, recommended tightening torque cannot be exceeded in order to avoid mechanical damage to metal roofing by bolts.

- Calculated allowable load on a single support brackets with span $1200 \mathrm{~mm}$, according to the manufacturer recommendations, is higher than measured holding strength 4,63 kN for roof slopes $0^{\circ}-23^{\circ}$. The manufacturer probably considered friction between snow and roofing at lower roof angles. For support brackets with span $800 \mathrm{~mm}$ is snow retention system design according to the manufacturer recommendations reliable for all roof slopes.

The holding strength of all tested linear snow retention systems depends also on mechanical properties of linear elements (fences, tubes), which were not subjected to the laboratory testing.

\subsubsection{Snow strap}

- Ultimate strength of individual tested snow straps varied widely, which could be caused either by measurement inaccuracies or different mechanical properties of tested brackets. The lowest value of ultimate strength was $1,07 \mathrm{kN}$.

- Even value of allowable load on snow strap for the worst scenario $(0,83 \mathrm{kN})$, calculated according to the manufacturer recommendations, was lower than measured ultimate strength $(1,07 \mathrm{kN})$. 
- The ultimate strength of snow strap is given by quality of particular product - steel grade, quality of processing, storage, handling on construction site etc., since they were plastically deformed.

This snow retention system, designed according to the manufacturer recommendations in combination with linear types snow retention system, can be stated as reliable.

\subsubsection{U-shaped snow guard}

- The average measured ultimate strength of U-shaped snow guard was 2,9 $\mathrm{kN}$ and exceeded even value of allowable load on snow guard for the worst scenario $0,83 \mathrm{kN}$, calculated according to the manufacturer recommendations.

- Average strength $0,53 \mathrm{kN}$, at which start of fastener screws rotation could have been sighted with the naked eye, was lower than value than allowable load on snow guard for the worst scenario. Fastener screws rotation causes that rubber seal does not rest on the roofing and screws penetration is not sealed effectively.

- The holding strength of U-shaped snow guard is given by mechanical properties of roofing since snow guard is fastened to the roofing only.

If roof reliability in terms of watertightness is neglected, U-shaped snow guard designed according to the manufacturer recommendations is reliable in terms of holding strength. However, the roof watertightness is endangered at higher allowable loads, therefore this snow retention fastening system should be stated as inappropriate.

\section{Measurement of friction between snow and roofing}

Second part of dissertation assignment was to determine static and dynamic frictional coefficient between snow and different types of roofing, in order to determine boundary conditions for the start of snow mass sliding upon individual types of roofing and potential impact zones of snow and ice sliding off the roofs.

\subsection{Method}

Friction was measured by method, which principle is to measure how large inclination angle between horizontal plane and inclined plane is necessary for a snow sample to start sliding downwards the roofing and for uniform motion of snow sample upon roofing. Static frictional coefficient $f_{s}$ and dynamic frictional coefficient $f_{d}$ is given by the equation:

$$
f_{s}=\tan \alpha, f_{d}=\tan \beta,[-]
$$

For measurement of friction, testing apparatus was designed and constructed. It is a steel frame with adjustable part, with dimensions $1 \times 2,5 \mathrm{~m}$, for adjusting the inclination angle in a range of 5 to 80 degrees. Adjustable part is designed in order to change segments with individual types of roofing. During the testing, the ambient and roofing surface temperature was monitored by thermometer Greisinger GMH 3350. The effort was to select the most commonly used types of roofing for sloped roofs in Slovakia. New products, not used, were subjected to the test. A total of four types of roofing systems were selected for the test:

- Natural clay roof tile,

- Galvanized metal sheet,

- Asphalt shingle,

- Stone coated steel metal roofing. 


\subsection{Results}

The most important findings observed during the testing are following:

- At negative roofing surface temperatures, between snow and roofing could be created such a strong adhesive forces, that snow does not start sliding upon the roofing even at steep roof slopes.

- Friction between snow and roofing is the lowest at positive roofing surface temperatures.

- Frictional coefficient between snow and roofing is affected by water film created by snow melting, which lubricate roofing surface.

- Frictional coefficient between snow and galvanized metal roofing is affected by water film created by snow melting, which lubricate roofing surface. At high value of snow water equivalent, in terms of tribology, the lubricated friction occurs between snow and roofing if thickness of water film is greater than surface roughness of metal roofing.

- Frictional coefficient between snow and natural clay roof tile is affected by water absorbency of tile, which does not allow the creation of significant water film on its surface.

- Frictional coefficient between snow and asphalt shingle and stone coated steel metal roofing is affected by water film created by snow melting and surface roughness, which reduces the effect of lubrication by melting water. Water film thickness does not reach the height of surface roughness, and in terms of tribology, solid/boundary or mixed friction occurs between snow and these types of roofing.

- The static coefficients of friction between the snow and selected types of roofing at positive surface temperatures of the roofing are calculated as the tangent of the angle at which the start of snow sliding upon the roofing occurred.

Table 1. Measured static coefficients of friction between snow and roofing at positive roofing surface temperature.

\begin{tabular}{|c|c|c|}
\hline Type of roofing & $\left.\beta{ }^{\circ}{ }^{\circ}\right]$ & $\mathbf{f}_{\mathbf{d}}[-]$ \\
\hline Snow / Galvanized metal sheet & 10 & 0,18 \\
\hline Snow / Natural clay roof tile & 30 & 0,58 \\
\hline Snow / Asphalt shingle & 40 & 0,84 \\
\hline Snow / Stone coated steel metal roofing & 55 & 1,43 \\
\hline
\end{tabular}

- The dynamic coefficients of friction between the snow and selected types of roofing at positive surface temperatures of the roofing are calculated as the tangent of the angle at which snow was sliding uniformly.

Table 2. Measured dynamic coefficients of friction between snow and roofing at positive roofing surface temperature.

\begin{tabular}{|c|c|c|}
\hline Type of roofing & $\boldsymbol{\alpha}\left[{ }^{\circ}\right]$ & $\mathbf{f}_{\mathbf{s}}[-]$ \\
\hline Snow / Galvanized metal sheet & $12,5 \pm 2,5$ & $0,22 \pm 0,05$ \\
\hline Snow / Natural clay roof tile & $32,5 \pm 2,5$ & $0,64 \pm 0,06$ \\
\hline Snow / Asphalt shingle & $47,5 \pm 2,5$ & $1,10 \pm 0,10$ \\
\hline Snow / Stone coated steel metal roofing & $67,5 \pm 2,5$ & $2,45 \pm 0,30$ \\
\hline
\end{tabular}




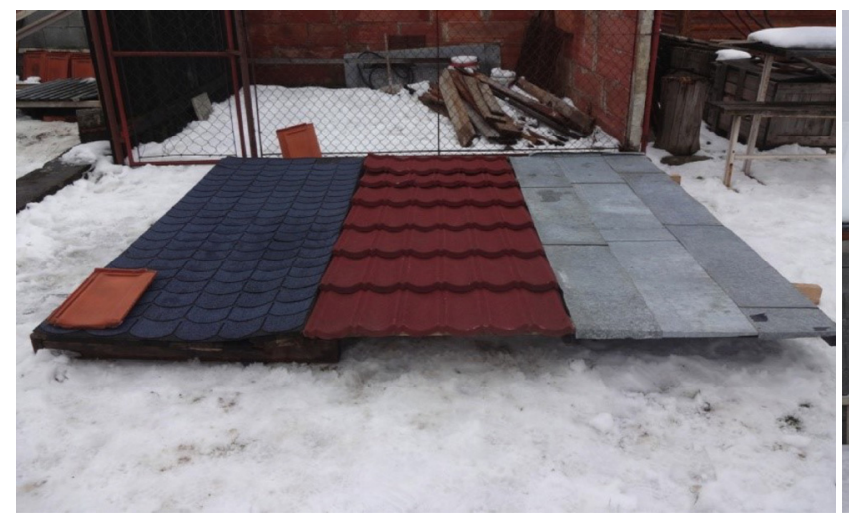

Fig. 7. Tested types of roofing.

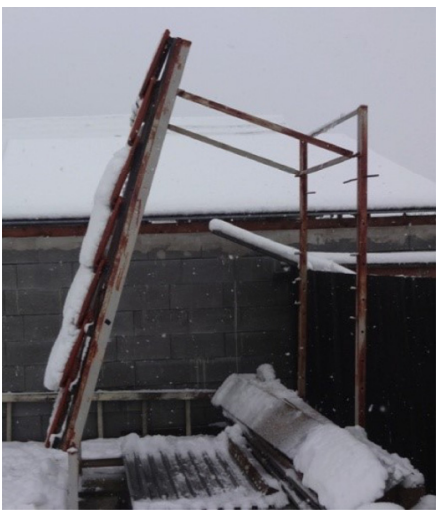

Fig. 8. Testing apparatus.

\section{Conclusion}

The snow on the roof issue is very broad topic. This issue involves a number of specific problems, which are closely related, resulting from the snow mass on the sloped roofs. One of these specific problems is movement of snow mass upon the roofing and falling off the roof itself. Consequences resulting from the snow and ice falling off the roof could be eliminated by appropriate design of snow retention system. The testing results of all selected snow retention systems confirmed that if you follow the design recommendation of manufacturers, the systems work reliably in terms of holding strength. The results of linear snow retention systems showed that their reliability could be improved by using non-linear elements, which help retain the snow mass over the entire roof surface. Manufacturers of tested linear snow retention systems recommend the same approach. If the maintaining of the roof reliability in terms of watertightness when possible extreme snow load occurs, the snow retention system for standing seam metal roofing (Snow rail) is the most reliable. On the other side, U-shaped snow guard failed this test. At particular loads, the fastening screws started to rotate and buckled the corrugated metal roofing and rubber seal did not rest on the roofing. That is the reason, why fastening of snow guards or entire snow retention system into to the roofing only with penetration is not inappropriate. If the penetration of the roofing is necessary, the snow retention system must be fasten to the support structure of the roofing. It is also necessary to create the rules in form of standard or some regulation for design and construction of snow protection system on sloped roofs, in order to prevent chaos in Slovak legislation associated with snow protection design and eliminate improper design and construction resulting in roof failures or catastrophes caused by snow falling off the sloped roofs.

\section{References}

1. Decree of the Ministry of Environment of the Slovak Republic No. 532/2002 (2002)

2. STN 73 1901:2005, Designing of roofs (2005)

3. MCA Guidelines for Commercial Roofing, Metal Roof design for Cold Climates

4. P. Kollar, Building research journal, 53, 137-154, (2005)

5. ÖNORM B3418:2012 Planung und Ausführung von Schneeshutzsystemen auf Dächern (2012) 